\title{
Autoethnography as an Authentic Learning Activity in Online Doctoral Education: an Integrated Approach to Authentic Learning
}

\section{Kyungmee Lee ${ }^{1}$}

Published online: 13 May 2020

(C) The Author(s) 2020

\begin{abstract}
Under the constructivist learning paradigm, which emphasises authenticity as a required condition for learning, distance educators have been striving to create authentic learning environments that reflect the real world. However, it is inevitably challenging to make an online learning environment authentic for learners when it is ultimately separated from their real-life contexts. Particularly, in online doctoral education, given the diversity among online learners, even defining "what is real and to whom" is a difficult task. This paper argues that the epistemological approach to authentic learning, based on the constructivist learning paradigm, is not sufficient to make online learning "authentically" meaningful. The paper introduces an alternative, ontological approach stemming from the transformative learning paradigm, and suggests autoethnography as one authentic learning activity that can effectively integrate the epistemological and ontological approaches to authentic learning in online doctoral education. Such a comprehensive conceptualisation of authentic learning, as an integrated process of both knowing and becoming, allows each doctoral student to become a more authentic self across their learning and living environments.
\end{abstract}

Keywords Authentic learning $\cdot$ Autoethnography $\cdot$ Online doctoral education $\cdot$ Epistemological approach $\cdot$ Ontological approach

\section{Introduction}

The constructivist learning paradigm emphasises authenticity (i.e., the quality of being real or true) as a required condition for meaningful learning (Jonassen 2010). Under the regime of that learning paradigm, educators and instructional designers have for decades been striving to create authentic learning environments that reflect the real world (e.g., Herrington and Oliver 2000; Ozverir et al. 2016; Rule 2006). While providing authentic learning activities, which are relevant to individual learners' real-life situations, instructional designers have also focused on facilitating learner reflection and collaborationon the grounds that this is the way in which problems are solved and knowledge is constructed in the real world (Scardamalia and Bereiter 1994). Yet, despite these continuing efforts, when the design of an online learning environment is ultimately separated from learners' real-life environments, it is inevitably challenging for instructional designers to make

Kyungmee Lee

k.lee23@lancaster.ac.uk

1 The Department of Educational Research, Lancaster University, County South, Lancaster, Lancashire LA1 4YD, UK online learning genuinely authentic to individual learners (Lee 2018a). In addition, given the increasing diversity among today's online students in terms of their needs, backgrounds, and learning and living conditions, even defining "what is real and to whom" is a difficult task.

When it comes to online doctoral education, there is mounting pressure on tutors to make learning authentic to their diverse student group (Lee and Oztok under review; Kung and Logan 2014). For many adults with multiple responsibilities in their personal and professional lives, doing doctoral study at a distance can be extremely burdening. In addition, most online doctoral students, who are also experienced professionals, come to an online doctoral programme with a considerable level of both real-life skills (accumulated through their working experiences) and academic knowledge (attained from their previous education). In order to maintain their motivation and will to learn, therefore, it is particularly important to help them situate their doctoral study in real-life contexts, making both their learning process and outcome meaningful (Kung 2017; Rockinson-Szapkiw et al. 2016). In other words, it would not be possible to expect online doctoral students to engage in a meaningful learning process, simply by providing new knowledge and skills, which are disconnected from their real-life situations. Given the huge distance of 
doctoral students' real world - not only from their tutors' but from each other's - the question of "what is real and to whom" becomes more complex to answer.

The aim of this paper is to reconceptualise "authentic learning," primarily with reference to online doctoral education contexts, but the reconceptualisation will be applicable across multiple distance learning contexts. The paper acknowledges that the ways in which authentic learning is currently defined and approached under the constructivist learning paradigm (e.g., designing authentic learning activities and facilitating collaborative knowledge construction) are meaningful. However, the paper will further argue that they are not sufficient to make online doctoral students' learning "truly" authentic. Aiming to address the limitations of the knowledgefocused approach to authentic learning, this paper will introduce an existence-focused approach stemming from the transformative learning paradigm and will suggest that distance educators and instructional designers integrate the two approaches in their pedagogical practices. The paper will further demonstrate that a comprehensive conceptualisation of authentic learning, as an integrated process of both knowing and becoming, can allow each doctoral student to become a more authentic self across their learning and living environments.

\section{Two Approaches to Authentic Learning in Literature}

There are, at least, two distinctive approaches to conceptualising authentic learning in the current literature related to online doctoral education. The first, which I call an "epistemological" approach, is based on the constructivist learning paradigm and the second, which I call an "ontological" approach, is based on the transformative learning paradigm. The former (epistemological) approach has been most evident in the literature concerning the design of online learning environments, which make learning contexts or scenarios more meaningful and relevant to individual learners and their real-life circumstances. The latter (ontological) approach is more prominently discussed in the literature concerning how adult learners learn and who adult learners are. That adult learning literature stresses the importance of enabling adult learners to be an authentic self throughout their learning process or to become a more authentic person as an outcome of their learning. Thus, the expected outcome of authentic learning, in the constructive learning paradigm, is new knowledge and skills, whereas the expected outcome of authentic learning, in the transformative learning paradigm is new perspectives and a greater sense of self- or social awareness.

\section{An Epistemological Approach}

One of the first attempts to make distance learning experiences more authentic for individual learners is documented by Herrington and Oliver (2000). They developed an instructional design framework for authentic learning environments by defining critical pedagogical elements of situated learning - in other words, a representative model of constructivist learning, which stresses removal of separation between the educational contexts where abstract knowledge is taught and the real-life contexts where knowledge needs to be used for problem-solving. The nine elements of their institutional design framework include: 1) Provide authentic contexts that reflect the way the knowledge will be used in real life, 2) Provide authentic activities, 3) Provide access to expert performances and the modelling of processes, 4) Provide multiple roles and perspectives, 5) Support collaborative construction of knowledge, 6) Promote reflection to enable abstractions to be formed, 7) Promote articulation to enable tacit knowledge to be made explicit, 8) Provide coaching and scaffolding by the teacher at critical times, and 9) Provide for authentic assessment of learning within the tasks. Among these nine elements of situated learning, many instructional designers have particularly focused on providing authentic activities, which are characterised by Reeves et al. (2002) as:

authentic activities match as nearly as possible the realworld tasks of professionals in practice rather than decontextualised or classroom-based tasks... Problems inherent in the activities are ill-defined and open to multiple interpretations rather than easily solved by the application of existing algorithms. Learners must identify their own unique tasks and sub-tasks in order to complete the major task... The task affords learners the opportunity to examine the problem from a variety of theoretical and practical perspectives, rather than allowing a single perspective that learners must imitate to be successful... Collaboration is integral to the task, both within the course and the real world, rather than achievable by an individual learner (p. 564).

Those suggested characteristics of authentic learning activities have effectively guided online educators' instructional design practices across different pedagogical contexts for some considerable time. Yet, while the characteristics remain in use in the form of design principles in the online learning literature (see Herrington et al. 2014), there have been growing reservations about the idea of instructional designers "designing" authentic learning environments and "providing" authentic learning activities. One of the earliest criticisms of the "designer-centred' (or 'teacher-centred') design practices dates back to 1998 when Petraglia argued that instructional designers had focused on "pre-authenticating learning environments" or 
"creating environments that are predetermined to reflect the real worlds" (p. 53), even though constructivism denies precisely such notions of pre-authentication or pre-determination. Petraglia concluded that pedagogical practices guided and dictated by the constructivist learning theory tend to overlook the original, fundamental, epistemological ideas of constructivism (see more in Lee 2018b).

For example, going back to the nine elements of situated learning (Herrington and Oliver 2000), it is noticeable that educators (not learners) who pre-decide which knowledge, and the way in which it will be used in learners' real-life settings; and who pre-determine the way learners need to perform their tasks and construct the knowledge. As Gulikers et al. (2005) argue:

it cannot be automatically assumed that an environment that is designed by educational developers as an authentic environment is also experienced as authentic by students... It can be questioned what the relevance is of an authentic learning environment that is perceived as authentic in the eyes of teachers but not in the eyes of students (p. 512-523).

In the recent educational context, with its growing diversity of student backgrounds, it is increasingly difficult to expect any single learning activity to be authentic to all learners at the same time - no matter how real (ill-defined, complex, reflective, etc.) the pre-designed activity is. In distance learning contexts, where there is a clear separation, at least in a physical sense, between students' learning environment and their reallife environments, it is even more challenging to make a learning environment authentic to everyone. For example, in the UK-based online doctoral programme in which the present Lee's (2019) teaching practice is situated, there are more than a hundred adult students, who are all educational professionals currently working at different institutions and living in different countries across the globe. Given those students' diverse professional, cultural, and personal circumstances, it seems impossible to provide any learning activity naturally authentic to all of them. Especially given that the real-worldness of any learning environments, in a more holistic sense that includes learning activities, processes and outcomes, will be differently experienced by each student, based on their own unique standpoint.

In addition, the design of authentic learning activities is often guided by the principle of "matching as nearly as possible" the real-world tasks and performances of professionals in practice (i.e., experts). However, the validity of such an expert-modelling principle can also be questioned, on the grounds that it may contradict other design principles of authentic activities - including the one suggesting that learners "identify their own unique tasks and sub-tasks in order to complete the major task" and "examine the problem from a variety of theoretical and practical perspectives, rather than allowing a single perspective that learners must imitate to be successful" (Reeves et al. 2002, p. 564). In other words, how can anyone possibly design a learning task both requiring learners to follow the ways in which "experts" would act in the real world and allowing learners to perform the task in their own unique way using diverse perspectives (not the single perspective of experts)? The very assumption that there are "the" professionals, whose knowledge and perspectives are more worthy than others', is also problematic in the current society in which multiple perspectives and forms of legitimate knowledge co-exist. In the online doctoral programme mentioned earlier, for example, all doctoral students are "the" professionals in their own working contexts; thus, both questions of which task is authentic and which ways of performing the task should be adopted need to be answered by themselves.

\section{An Ontological Approach}

Alternatively, the ontological approach to conceptualising authentic learning in adult learning literature draws its focus on "enabling" or "empowering" each adult to be an authentic self in their learning contexts, and furthermore, to become a more authentic person in their real-life contexts as an outcome of their learning. Such an existence-focused approach in adult learning has emerged from different philosophical and theoretical grounds (Kreber et al. 2007). One dominant idea underpinning the ontological approach is Heidegger's (1962) distinction between authenticity and inauthenticity. Heidegger posited that to live authentically, people need to be able to confront their own limitations and open up different possibilities for their existence (i.e., ways of being, living, and interacting with others) beyond those defined and determined by social norms and/or personal habits. When people exist inauthentically, they do not (or forget to) care for themselves or others - they live without the will to free themselves from their own limitations. When people exist in what Heidegger called everydayness, they tend to be too busy with everyday affairs and caught up in their daily routines, thereby becoming indifferent to re-imagining their own possibilities (Zimmerman 1986).

Some adult educators and theorists further argue, based on the Frankfurt School of Critical Theory (for example, Adorno 2003), that authentic existence involves critical reflection on social structures and historical development of the self and self-awareness. Thus, people, to live authentically, need to be able to ultimately recognise real emancipatory possibilities and challenge the existing power relationships in a certain society, which limit their possibilities of being. Although there is a nuanced distinction between the political aim (or endpoint) of Heidegger's and Critical Theorists' ideas of being an authentic self, there is a shared focus, in both theoretical grounds, on developing new perspectives and a greater sense 
of self- or social awareness as a learning outcome. In other words, existence-focused authentic learning, in both a selforiented (in Heidegger 1962) and a social-oriented (in Adorno 2003) sense, is aligned with the transformative learning paradigm:

New information is only a resource in the adult learning process. To become meaningful, learning requires that new information be incorporated by the learner into an already well-developed symbolic frame of reference, an active process involving thought, feelings, and disposition. The learner may also have to be helped to transform his or her frame of reference to fully understand the experience (Mezirow 1997, p. 10).

Transformative learning is a process in which individuals experience radical changes in their perspectives through critical reflection and rational dialogue (Mezirow 2000). Transformative learning brings about "a wholistic change in how a person both affectively experiences and conceptually frames his or her experience of the world when pursuing learning that is personally developmental, socially controversial, or requires personal or social healing" (Yorks and Kasl 2006, p. 46). That is, according to the transformative learning paradigm, the outcome of authentic learning includes cognitive, affective, and behavioural changes, which fully transform the ways in which the person sees, feels, and interacts with others in society. Even though knowledge-focused authentic learning also brings about affective and habitual changes as an outcome (see, Herrington et al. 2009), one of the features that most distinguished the transformative learning paradigm from the constructivist learning paradigm is its strong emphasis on affectedness - not only as an outcome but also as a trigger and beginning of learning. Heidegger (1962) defines "affectedness" as a state of mind or mood, that is, a fundamental condition of being-in-the-world and relating-to-the-world (and others). Such a state of mind or mood affects how adult learners feel, sense, and direct their learning and living situations. (Only) when adult learners feel and sense the strong need or will to transform their perceptions and practice to become a more authentic self in the world, will authentic learning happen.

Going back to the example of the UK-based online doctoral programme, most of the doctoral students originally join the programme with a rather instrumental motivation to earn a doctoral degree for other purposes such as being promoted and getting a new job (see Lee and Oztok under review). Those doctoral students with fulltime jobs and other social and personal responsibilities tend to perceive distance learning as a convenient tool to earn a doctorate without sacrificing their personal and social lives. However, in their new learning and living conditions, doctoral students often face a series of "disorienting dilemmas," moments when their expectations and experiences do not match, when everyday habits and new ways of being come into conflict, and when frames of reference are destabilised and questioned (Mezirow 2000). Those moments trigger students' "critical reflection" including self-examination of their experience and critical assessment of their assumptions; and "rational dialogue", which involves sharing experiences with others and exploring alternative approaches to the situations among their peers. Through the processes, students plan different actions, thereby acquiring knowledge for implementing their plans, and reintegrating "new perspectives" into their lives (Herbers 1998, as cited in Glisczinski 2007).

The implication is that, under the transformative learning paradigm, one of the most essential characteristics of authentic learning activities is to provide moments that trigger disorienting dilemmas and to provoke affectedness (i.e., the will to engage with critical reflections and rational dialogues). Students, by experiencing (and dealing with) such moments and affectedness, experience multiple "new becomings" such as: becoming a distance learner, becoming a doctoral researcher, becoming a better professional, and becoming a scholar. Through these transformative processes, therefore, doctoral students learn authentically, which leads them to become a more authentic self both in their learning environment and their real-life contexts. Such authentic learning experiences are, however, often accompanied by negative emotions (e.g., a sense of anger, distress, doubts, denial, etc.). Despite the necessity of experiencing those emotions, if learning is to be truly authentic, by no means is that an easy experience; in fact, such negative emotions can result in failures (i.e., student drop-outs) rather than meaningful learning in online doctoral programmes. In fact, many students in the online doctoral programme find such emotions overwhelming and discouraging. Therefore, supporting their emotional experiences of challenging their current selves and becoming a different person (hopefully, a better one) is a critical task for tutors in those programmes.

It is worthwhile to note that some critical theorists, especially those with strong political aspirations for social transformation, may criticise the individualistic nature of transformative learning, which mainly focuses on individual learners' experiences and perspective transformations. Despite the perceived lack of criticality and social orientation in transformative learning, it is commonly observed in online doctoral programmes that as individual learners become a more authentic self, that has positive effects not only on themselves but also on their neighbouring others and communities. 


\section{An Integrated Approach to Authentic Learning and Autoethnography}

In this section, I will argue that tutors in online doctoral programmes can better support students' authentic learning experiences by combining both the epistemological approach and the ontological approach in their pedagogical practice. Some may argue that there is no clear distinction between the epistemological approach and the ontological approach — or, more specifically, between the constructive learning paradigm and the transformative learning paradigm. This paper also acknowledges the possibility that situated learning may, ultimately, lead to transformative learning, thereby producing new perspectives; or, in other words, the transformative learning may happen when doctoral students perform constructivist learning tasks in order to develop new knowledge and skills. In fact, it is often noted that online programmes, designed according to principles of epistemological authentic learning, not only yield knowledge and skills but also shape new attitudes and nurture new actions or habits-often understood as learning addressing all four learning domains, which are cognitive, affective, psychomotor, and conative (see Herrington et al. 2009).

Despite a certain degree of commensurability between the two, however, this article sees the value of first "explicitly" separating the two and then "intentionally" integrating the two, highlighting characteristics and limitations of each (see Table 1). A lack of political direction and emotional emphasis in the epistemological approach and a lack of pedagogical direction and practical design principles in the ontological approach can thus be complementarily addressed when both approaches are fully integrated into online doctoral programmes.

\section{Autoethnography}

Autoethnography is a qualitative research attempt to collect stories about the self, and then to understand the shared aspects of general culture and the cultural practices embedded and represented in those self-narratives (Chang 2008). By using autobiographical stories and self-reflection on those stories as main data sources, researchers can explore and access their complex inner thoughts and emotions and, thus, develop a more comprehensive understanding of social phenomena. Adams et al. (2015) describe the general principles of doing autoethnography, as follows: 1) autoethnographers foreground personal experiences (often focusing on sadness and discomfort) in their research and writing; 2) autoethnographers illustrate the sense-making processes of their experiences; 3 ) autoethnographers use and show reflexivity to turn back to their social identities and relationships, in order to consider how those influence their sense-making processes; 4) autoethnographers offer insider knowledge of cultural phenomena by researching and writing from the lived, inside moments of their experiences; 5) autoethnographers describe and critique cultural norms and practices; and 6) autoethnographers seek reciprocal responses from audiences.

The purpose of autoethnography, as a research project, is fundamentally to produce new knowledge that enhances our in-depth understanding of a chosen subject. In autoethnography, an autoethnographer (researcher) chooses the subject of their inquiry, which should be personally meaningful as well as socially, culturally, and academically significant. Online doctoral students, who are novice researchers, can develop their research knowledge and skills by conducting an autoethnographic investigation, which allows them to select and examine their real world problems; that is, one situating

Table 1 A comparison of two approaches to authentic learning

\begin{tabular}{|c|c|c|}
\hline & Epistemological approach & Ontological approach \\
\hline $\begin{array}{l}\text { Philosophical } \\
\text { foundations }\end{array}$ & $\begin{array}{l}\text { Knowledge-focused: Constructivist } \\
\text { learning paradigm }\end{array}$ & Existence-focused: Transformative learning paradigm \\
\hline Learning purpose & Constructing meaningful knowledge & Becoming a more authentic person \\
\hline Learning process & $\begin{array}{l}\text { Problem-solving, collaborative } \\
\text { knowledge production, reflection }\end{array}$ & $\begin{array}{l}\text { Critical reflection, rational dialogue, } \\
\text { multiple becomings }\end{array}$ \\
\hline Learning outcome & New knowledge and skills & New perspectives and critical awareness \\
\hline Learning model & Situated learning & Transformative learning \\
\hline Tutors' roles & $\begin{array}{l}\text { Instructional designers: Designing } \\
\text { authentic learning activities and facilitating knowledge } \\
\text { production }\end{array}$ & $\begin{array}{l}\text { Emotional supporters: Triggering disorienting } \\
\text { dilemmas and providing emotional supports }\end{array}$ \\
\hline Pedagogical limitations & $\begin{array}{l}\text { A lack of political direction and } \\
\text { emotional emphasis }\end{array}$ & $\begin{array}{l}\text { A lack of pedagogical direction and practical design } \\
\text { principles }\end{array}$ \\
\hline
\end{tabular}


their online learning in their real-life contexts. In this scenario, autoethnography can be perceived as an "authentic learning activity", designed to serve doctoral students' situated learning based on the constructive learning paradigm.

On the other hand, autoethnography embarks from a researcher's narrative exploration of their transformative moments (i.e., epiphanies) or emotional struggles (i.e., disorienting dilemmas). Through the inquiry processes, autoethnography often results in other epiphanies and new perspectives and actions; in this sense, there is a strong parallel between autoethnography and transformative learning. Furthermore, autoethnographers critically engage with "the process of figuring out what to do, how to live, and the meaning of their struggles" (Bochner and Ellis 2006, p. 111) and so ultimately, strive to make life (not only their own but the life of their neighbouring others) better. That is, the "political direction" in autoethnography (Adams et al. 2015, p. 2) is wellaligned with the ontological approach to authentic learning. Online doctoral students, by doing an autoethnography, may develop new perspectives and a critical self- and social awareness, through which they experience "becoming a more authentic self" simultaneously as doctoral student, professional, educator, colleague, and even as friend.

\section{An Illustration: Autoethnography in Online Doctoral Education}

The online doctoral programme discussed in this article consists of two academic phases: in Part 1, approximately thirty doctoral students, who are all in-service educational professionals, enter the programme at the same time and take six online modules together for the first two years. This cohortbased collaborative learning process is effectively facilitated by a range of social activities (e.g., group discussions, peerreviews), and by annual residential meetings, during which all cohort members come to campus and participate in face-to- face sessions. Subsequently, students move to Part 2, in which they independently work on their thesis project under supervisory guidance for a period of two to three years. The author's research methodology module is the very first module of the programme, which lasts for 20 weeks. The purpose of the module is to help online doctoral students construct a solid understanding of how to plan, conduct, and evaluate educational research. The major assignment of the module is to plan, conduct, and write, supported by the module tutor, a 5500word autoethnography on a research specific topic chosen by each student, which enables students to research issues that arise out of their personal experiences.

The module is structured around three different learning phases: i) Phase I (10 weeks), during which students independently read suggested materials and participate in online group discussions guided by the tutor, while planning their autoethnography assignment; ii) Phase II (6 weeks, including a week-long residential meeting), during which students conduct their autoethnography and write and submit their draft assignment; and iii) Phase III (4 weeks), during which students review two of their peers' drafts, revise their draft based on tutor and peer feedback, and evaluate their learning. In the module, students are provided with opportunities to think (or re-think) and discuss how to conduct good research and what a good researcher could/should do. Students come to the module with their own pre-conceptions of what good research looks like and what rigorous research methods are, which have been developed from their previous research and learning experiences (i.e., some from their Master's courses and others from their involvement in different research projects). Most of them initially hold a relatively positivist view on research, for example being in favour of quantitative research methodologies, which is the dominant tradition in the academic field that the doctoral programme is concerned with.

This group of positivist doctoral researchers, therefore, faced an early disorienting dilemma when the first reading assignments and discussion questions were posed, as follows:

\section{Please bring one paragraph, which you have found particularly interesting, which made you motivated to become an autoethnographer. Also, please bring another paragraph, which you have found particularly uncomfortable, which made you worried about doing an autoethnography in this module. Please tell us why you have felt in such ways and check if your peers have felt the same ways as you have.}

Lynn, one student in the previous cohort of the programme picked the following paragraph as her uncomfortable paragraph in response to the first discussion question: 
Autoethnography provided me-and can provide you - a method for exploring, understanding, and writing from, through, and with personal experiences in relation to and in the context of the experiences of others. In autoethnography, 'proximity, not objectivity, becomes an epistemological point of departure and return' (Adams et al. 2015, p. 23).

She then commented on the paragraph as follows:

It is the last sentence of this paragraph which makes me feel uncomfortable. The lack of objectivity, that very essence of research which is the aspiration for both my own and my students' research, is presented as being redundant... Can any research be entirely objective? Even if it is not always successfully achieved, it feels a case of 'throwing the baby out with the bathwater' to totally dismiss the concept of producing research which aims to focus on the findings of the research rather than the personality, beliefs and values of the researcher. Amusingly, I find myself re-reading that last sentence referring to personality, beliefs and values and the immediate thought that comes into my mind is 'but that can't be objective' and I remind myself that it's not meant to be.

As shown by this brief example, autoethnography, which is a radically qualitative and subjectivist research methodology, can play a significant role in doctoral students' authentic learning processes. Reading and learning about autoethnography triggered the essential moments of disorientating dilemma concerning doctoral students' research knowledge and researcher identities, making them feel "uncomfortable". Such feelings encouraged students to continue their "critical reflection" on their emotional reactions about doing autoethnography. Students were asked to articulate, analyse, and share their feelings online with their peers in the module, through which students became further engaged in "rational dialogues" with one another. For example, seven other students replied to Lynn's initial post above; and none of those students was hesitant to admit that they were also struggling not only to obtain new knowledge but also to accept new perspectives, which were very different from their established views on rigorous and "objectivist" research.

Sam, another student also wrote a similar post to Lynn's, which illustrated his negative initial feelings about autoethnography because of its lack of objectivity. He, however, picked the following paragraph as his interesting one:

As our stories illustrate, autoethnography is a method that allows us to reconsider how we think, how we do research and maintain relationships, and how we live. Our stories of coming to the method tell of moments when excluding or obscuring personal experiences felt uncomfortable, even impossible. Our stories are not unique to us; they also illustrate a change in how researchers approach their work (Adams et al. 2013, p. 8).

He then reflected on the paragraph, concluding that:

Since I had not come across autoethnography previously, the [above] paragraph was both interesting and fascinating when I first read it... In my experience, research has been about finding out something, but removing myself from the situation, being careful not to display any personal bias. So when the opening sentence of this paragraph asks us to 'reconsider how we think, how we do research and maintain relationships, and how we live' I thought, this feels quite powerful to me, thinking in terms of why I'm undertaking this programme of study, and how I can relate it to my civic and volunteering interests. All the advice in searching for a research topic tells us to find something we're interested in, something we're passionate about and this toe-dipping into the waters of autoethnography might suit me very well. I don't want to be distant or removed from my research, I want to live it!

During the discussion week, students encountered different perspectives and feelings towards autoethnography - those both similar to theirs and different from their own. As Mezirow (1997) pointed out, however, "the learner may also have to be helped to transform his or her frame of reference to fully understand the experience" (p. 10). Students learning and doing autoethnography experiences were supported and facilitated by other structured module activities. In particular, guided online discussions like the above examples helped expose students to multiple perspectives and prompt meaningful reflections and rational dialogues about autoethnography - essential steps for students to transform their research perspectives. After the online discussions, through which students critically reflected on their initial emotional reactions to 
autoethnography and collaboratively enhanced their understanding about the particular research methodology, students were next guided to design and plan their own autoethnography project.

Let's start brainstorming now! What are you going to do about the module assignment? Is the notion of autoethnography still messy in your head? If then, you can start with your very personal experiences. Tell us one of your stories (related to learning and teaching in general) that have made you feel uncomfortable, uneasy, difficult, unclear, etc.; so you feel like it is worth spending some time and effort on unpacking and better understanding the story (also, making yourself feel better!). Where you are/were/have been in that story and who else is in that story? Also, tell us why it may be worthwhile for others to listen to the story.

In response to the tutor's invitation, all students posted their own stories, including a great deal of information about their personal and professional lives, in which their autoethnography projects (i.e., authentic learning) were situated. In those stories, students were not only online doctoral students; but also parents (a single parent), teachers (who was verbally abused by students), doctors (who was struggling with establishing a professional identity in a resource-poor country), educational technologists (who did not feel valued and respected by other university staff) and grown-up women (whose childhood dream to be a scientist was stopped by her parents and teachers). Those stories, originally shared in Week 4 , were gradually developed as autoethnography projects; such a developmental process for each student was supported by a series of sub-tasks in the module, including submitting a one-page research proposal (Week 5), followed by a final research proposal submission (Week 10). Each sub-task also involved and generated different moments of disorienting dilemmas, critical reflections, and rational dialogues among the student cohort and the tutor - who were not only trying to help each other's epistemological authentic learning but also ontological authentic learning. This is particularly important since there is a potential risk that, in utilising autoethnography as a learning activity, doctoral students may undergo very painful emotional and psychological experiences while digging into their memories and moments of struggles. That risk has been already noticed by other autoethnographers who have worked with doctoral students on their autoethnographic projects (Doloriert and Sambrook 2009; Holman Jones et al. 2013).

Many tutors in online doctoral programmes may find that giving emotional support to their students is burdensome or outside the boundaries of their professional expertise. In this sense, building a supportive learning community among the cohort-as often stressed by epistemological authentic learning - can be critical (Lee and Brett 2015). In the investigated module, online discussions enabled doctoral students to become an authentic person, sharing emotions and struggles with their peers, despite their irreducible distance from them. Subsequently, students could get to know each other not remotely as a peer-student only existing in the learning environment, but as a real person with a great level of authenticity and social proximity. Such a strong sense of proximity more effectively facilitated and supported students' transformative learning processes of becoming both an online doctoral student and an autoethnographer researching their own real-life practices and contexts.

One of the important methodological characteristics of autoethnography in this regard is its focus on collecting data from a researcher's memories; there are always others existing in those memories since the researcher, as a social being, interacts with other social beings in their everyday life. Thus, autoethnographers, in their data collection and analysis processes, naturally have rational dialogues with those important others, who can help them to create more accurate "collective" memories or broaden their perspectives by adding different interpretations or reactions to the recalled events. For example, Jennifer whose study involved examining her own experiences in parenting her teenage daughter, who she perceived was suffering from excessive use of social media, wrote in her final proposal:

As autoethnography is very much based on my experiences, feeling and thoughts I plan to discuss my research with my partner to aim for as accurate an account of information as possible. He, along with my daughter, will also be my guide to what information to share and what should remain private. To enhance my research further I intend to send a (parent \& teenager) online questionnaire to volunteers to investigate their perceptions and opinions around social media. 
Through such dialogues, which included aspects that happened within the online learning environment and in each student's real-life context, students gradually deepened their understanding of social and cultural events as well as the self and the others in those events, which eventually led to meaningful changes in their frame of reference. The last stage of the transformative learning process is to plan a different action, acquire knowledge for implementing the plan and reintegrate the new perspectives into one's life. The last stage of autoethnography is to write and share one's autoethnography (i.e., research report) with others in order to achieve the ultimate aim of the autoethnography, which is to figure out what to do and how to live, and in so doing to make one's (and others') life better. In Week 16, all students submitted their draft autoethnographies and embarked on a peer-review process, in which each student reviewed and provided comments on two of their peers' drafts. That is, in this module, a submitted draft autoethnography was reviewed by three people (two peer-students and a module tutor). This was another valuable opportunity for students to have a rational dialogue and review their newly constructed research knowledge and perspectives, as Sara reflected:

The autoethnographic experience is something that I found really useful and actually enjoyable, and the process of our first peer review (of many I'm sure) although uncomfortable, was a nudge towards betterment. This experience will drive me on to be a much-improved researcher and author - so thank you very, very much to [Peer 1] and [Peer 2] for their time and thoughtful comments.

\section{Conclusion: Becoming an Authentic Self}

At the end of the module, after submitting their final autoethnographies, students posted their self-reflections online and most students clearly articulated their authentic learning outcomes, including both new knowledge and perspectives. In addition to obtaining new understandings and skills for autoethnography (or qualitative research), most students seemed to experience a certain degree of change in their self-perceptions and their research paradigm. For example, in Peter's case below, based on his newly constructed knowledge, his perception of himself - as a supervisor, a colleague, and an academic - was transformed. As he said:

At the start of this module, despite having supervised Masters students for many years, I was anxious that my understanding of research philosophies and methodologies was too superficial. I was also concerned that I would be exposing this uncertainty to new colleagues. The first reading was hard... I wasn't alone in this feeling... That was a great boost... As we began to exchange our understanding, views and opinions and dialogue grew the value of being part of an online collaborative learning community became even more apparent. Then there was autoethnography! As a research method, many of us questioned why... Asking me to use this methodology challenged my research preconceptions in a very positive way. I will in future be open to new methodologies. Have I grown academically as a consequence of this module? The answer is a definite yes. I can see already how I have changed as an academic whether it is through my supervision of dissertations or the application of my newfound understanding of my own research. (emphases in original)

Another student, Jane talked about her learning more dramatically, as follows:

No longer a Positivist! I really enjoyed this module. The self-directed and peer-to-peer learning suited my learning style quite well. I am delighted to report that my knowledge of research studies has vastly improved... The fact that we were 'advised' to choose an autoethnographical methodology really opened my eyes. Prior to this study, I would have considered myself a positivist, now I'm not so sure! The subjective is so much more interesting than the objective. (emphases in original)

The above comments illustrate how transactional distance among online doctoral students (and their tutor) has been effectively reduced and optimised; so that students have experienced emotional and cognitive proximity throughout their learning (Moore 1993). The learning task was well-structured and expected learning outcomes were clearly communicated to the students while the task itself requires each student to have a high degree of autonomy in their own learning processes as a distance learner as well as a doctoral researcher. A range of sub-tasks was strategically designed to enable and facilitate teacher-to-student and student-to-student dialogues at multiple points of the course duration to increase the level of connectedness between students and their online learning environment. In conclusion, in the online doctoral programme, autoethnography served as an authentic learning activity; through learning about autoethnography and designing, doing, and writing autoethnography, online doctoral students were able both to learn new knowledge and to become a more authentic person - a better researcher, student, teacher, professional, and parent.

This paper suggests, therefore, that distance educators expand their conceptualisation of authentic learning, to integrate both the epistemological approach and ontological approach, if they are to make learners' online learning genuinely authentic or authentically meaningful. In practice, distance educators can set up an overall module structure and provide a range of resources and opportunities for students to engage with their 
autoethnography — however, no more than that! There is no need to pre-authenticate learners' learning experiences by developing specific problem-solving scenarios and learning activities since autoethnography itself enables each student to identify their own meaningful problem and situate the activity in their personal context. Instead, distance educators need to be ready to walk with students through their transformative learning journey, which is likely to evoke different emotional experiences. Educators may need to pay careful pedagogical attention to students' emotional responses and attempt to utilise them more productively to make learning more authentic at the ontological level.

Acknowledgements I am grateful to the editors of this special issue as well as the anonymous reviewers for their helpful comments that contributed to the present version of this article. Further, I wish to thank my dedicated doctoral students who made this reflection possible and Brett for his constructive suggestions on an earlier version of this article.

Open Access This article is licensed under a Creative Commons Attribution 4.0 International License, which permits use, sharing, adaptation, distribution and reproduction in any medium or format, as long as you give appropriate credit to the original author(s) and the source, provide a link to the Creative Commons licence, and indicate if changes were made. The images or other third party material in this article are included in the article's Creative Commons licence, unless indicated otherwise in a credit line to the material. If material is not included in the article's Creative Commons licence and your intended use is not permitted by statutory regulation or exceeds the permitted use, you will need to obtain permission directly from the copyright holder. To view a copy of this licence, visit http://creativecommons.org/licenses/by/4.0/.

\section{References}

Adams, T. E., Holman Jones, S., \& Ellis, C. (2015). Autoethnography: Understanding qualitative research. New York, NY: Oxford University Press.

Adorno, T. (2003). The jargon of authenticity. London: Routledge (Original work published 1964).

Bochner, A. P., \& Ellis, C. (2006). Autoethnography. In G.J. Shepherd, J. St. John, \& T. Striphas. (Eds.), Communication as...: Perspectives on theory (pp. 110-122). Thousand Oaks: Sage Publications.

Chang, H. (2008). Autoethnography as a method. Abingdon, UK: Taylor $\&$ Francis.

Doloriert, C., \& Sambrook, S. (2009). Ethical confessions of the "I" of autoethnography: The student's dilemma. Qualitative Research in Organizations and Management: An International Journal, 4(1), 27-45.

Glisczinski, D. J. (2007). Transformative higher education: A meaningful degree of understanding. Journal of Transformative Education, 5(4), 317-328.me.

Gulikers, J. T., Bastiaens, T. J., \& Martens, R. L. (2005). The surplus value of an authentic learning environment. Computers in Human Behavior, 21(3), 509-521.

Heidegger, M. (1962). Being and time (J. Macquarrie \& E. Robinson, Trans.). London: SCM. (Original work published 1927).

Herbers, M. S. (1998). Perspective transformation in preservice teachers, Unpublished doctoral dissertation. Tennessee: University of Memphis.

Herrington, J., \& Oliver, R. (2000). An instructional design framework for authentic learning environments. Educational Technology Research and Development, 48(3), 23-48.
Herrington, J., Reeves, T. C., \& Oliver, R. (2009). A practical guide to authentic e-learning. New York, NY: Routledge.

Herrington, J., Reeves, T. C., \& Oliver, R. (2014). Authentic learning environments. In Handbook of research on educational communications and technology (pp. 401-412). New York, NY: Springer.

Holman Jones, S. H., Adams, T., \& Ellis, C. (2013). Introduction: Coming to know autoethnography as more than a method. In Handbook of autoethnography (pp. 17-48). London: Routledge.

Jonassen, D. H. (2010). Learning to solve problems: A handbook for designing problem-solving learning environments. Routledge.

Kreber, C., Klampfleitner, M., McCune, V., Bayne, S., \& Knottenbelt, M. (2007). What do you mean by "authentic"? A comparative review of the literature on conceptions of authenticity in teaching. Adult Education Quarterly, 58(1), 22-43.

Kung, F. W. (2017). Perceptions and career prospects of the distance doctor of education degree: Voices from the mid-career ELT tertiary practitioners. Innovations in Education and Teaching International, 54(1), $42-52$.

Kung, M., \& Logan, T. J. (2014). An overview of online and hybrid doctoral degree programs in educational technology. TechTrends, 58(4), 16.

Lee, K. (2018a). Everyone already has their community beyond the screen: Reconceptualizing online learning and expanding boundaries. Educational Technology Research \& Development., 66, 1255-1268.

Lee, K. (2018b). Discursive effects of a paradigm shift rhetoric in online higher education: Implications on networked learning research and practice. In N. B. Dohn, S. Cranmer, J. A. Sime, M. de Laat, \& T. Ryberg (Eds.), Networked learning: Reflections and challenges. New York, NY: Springer.

Lee, K. (2019). Transformative learning in online doctoral studies: Autoethnographic dialogue as a learning and research method. In M. Spector, B. Lockee, \& M. Childress (Eds.), Learning, design, and technology: An international compendium of theory, research, practice and policy. New York, NY: Springer.

Lee, K., \& Brett, C. (2015). Dialogic understanding of teachers' online transformative learning: A qualitative case study of teacher discussions in a graduate-level online course. Teaching and Teacher Education, 46, 72-83.

Lee, K., \& Oztok, M. (under review). Conceptualising online doctoral education: A relatively short paper on a considerably long journey of doing a PhD online.

Mezirow, J. (1997). Transformative learning: Theory to practice. New directions for adult and continuing education, 1997(74), 5-12.

Mezirow, J. (2000). Learning as transformation. Critical perspectives on a theory in progress. San Francisco: Jossey-Bass.

Moore, M. G. (1993). Theory of transactional distance. Retrieved from http:// www.c31.uni-oldenburg.de/cde/support/readings/moore93.pdf

Ozverir, I., Herrington, J., \& Osam, U. V. (2016). Design principles for authentic learning of English as a foreign language. British Journal of Educational Technology, 47(3), 484-493.

Reeves, T. C., Herrington, J., \& Oliver, R. (2002). Authentic activities and online learning. Retrieved from https://ro.ecu.edu.au/cgi/ viewcontent. cgi?article $=4899 \&$ context $=$ ecuworks

Rockinson-Szapkiw, A. J., Spaulding, L. S., \& Spaulding, M. T. (2016). Identifying significant integration and institutional factors that predict online doctoral persistence. The Internet and Higher Education, $31,101-112$.

Rule, A. C. (2006). The components of authentic learning. Journal of Authentic Learning. Retrieved from http://hdl.handle.net/1951/35263

Scardamalia, M., \& Bereiter, C. (1994). Computer support for knowledge-building communities. The Journal of the Learning Sciences, 3(3), 265-283.

Yorks, L., \& Kasl, E. (2006). I know more than I can say: A taxonomy for using expressive ways of knowing to foster transformative learning. Journal of Transformative Education, 4(1), 43-64. 
Zimmerman, M. (1986). The development of Heidegger's concept of authenticity. Eclipse of the self. (Rev. ed.). Athens: Ohio University Press.
Publisher's Note Springer Nature remains neutral with regard to jurisdictional claims in published maps and institutional affiliations. 